Review Article

\title{
Current state of pharmacology and therapeutics in irritable bowel syndrome with special reference to brain-gut axis
}

\author{
Suryaprakash Mishra ${ }^{\mathrm{a} *}$, Alok Singh ${ }^{\mathrm{b}}$, B. L. Pandey ${ }^{\mathrm{a}}$
}

\begin{abstract}
${ }^{a}$ Department of Pharmacology, Institute of Medical Sciences, Banaras Hindu University, Varanasi-221005, Uttar Pradesh, India,

${ }^{\mathrm{b}}$ Department of Pharmacology, G.R. Medical College, Gwalior-474001, Madhya Pradesh, India
\end{abstract}

Received: 15 January 2013

Accepted: 27 January 2013

\section{*Correspondence to:}

Dr. Suryaprakash Mishra,

Email: spmishra84@gmail.com

(C) 2013 Mishra S et al. This is an open-access article distributed under the terms of the Creative Commons Attribution License, which permits unrestricted use, distribution, and reproduction in any medium, provided the original work is properly cited.

\section{INTRODUCTION}

Irritable bowel syndrome (IBS), the most common functional bowel disorder, accounts for $20-50 \%$ of gastroenterology referrals leading to poor quality of life of patients and enormous burden on healthcare costs. ${ }^{1}$ Multifactorial etiology, poor understanding of the nonspecific triggering factors, symptom based diagnosis of exclusion and lack of a demonstrable structural or biochemical abnormality make its management difficult and unsatisfying for the patient, especially during the periods of exacerbations, called visceral hypersensitivity.

The goals of IBS therapy are to provide global relief of the multiple symptoms of IBS and to relieve single IBS symptoms. Although traditional IBS therapies (e.g., laxatives, antidepressants, antispasmodics, and bulking agents) are useful for some patients in relieving single IBS symptoms, patients generally are dissatisfied with their overall efficacy and tolerability. Development of new visceral analgesics, focusing on newer knowledge and understanding of brain gut axis, neuro-enteric regulation and concerned neurotransmitters and receptors is promising, but so far, the development of therapies aimed at reducing this hyperalgesia (visceral analgesics) has been only partially successful despite preclinical

\begin{abstract}
Irritable bowel syndrome (IBS), principal morbidity being visceral hypersensitivity, consumes significant speciality gastroenterologic and general practitioner's care. The complex etiology perhaps varying among the patients makes therapeutic address very challenging. Continuous researches on neurophysiological aberrations in IBS have continued. The drugs and the neurophysiological understanding with regard to addressing visceral hypersensitivity are relevant to be appraised. The translation of research wisdom into clinical practice may be facilitated by gastroenterology experts. The issues of effectiveness of the options in general and in particular patients may thus be addressed.
\end{abstract}

Keywords: Irritable bowel syndrome, Visceral hypersensitivity, Brain-gut axis, Neurotransmitters evidence supporting the potential usefulness of several preclinical compounds aimed at peripheral as well as central targets. A better characterization of normal as well as abnormal visceral pain perception (e.g. central pain amplification) and underlying mechanisms (sensory, cognitive, and emotional) in human patients is required before more effective drug development is possible. ${ }^{2}$

The current review analyses various phamacotherapeutic options available for management of visceral pain, targeting various receptors and neurotransmitters on the brain-gut axis at peripheral, spinal and supra-spinal levels. The system of sensory motor control of the gut has been termed the 'brain-gut axis'. The sensory innervation of the gut is two-fold, with a thoraco-lumbar spinal pathway and a vago-sacral pathway. The motor arms of these pathways are termed sympathetic and parasympathetic, respectively.

\section{PHARMACOLOGY OF PERIPHERAL VISCERAL} NOCICEPTIVE AFFERENT PATHWAYS

Noxious stimuli may cause the peripheral release of several inflammatory mediators such as $\mathrm{K}+, \mathrm{H}+$, adenosine triphosphate, 5-hydroxytryptamine (5-HT), bradykinins and prostaglandins. ${ }^{16,17}$ They lead to the activation and peripheral sensitization (PS) of nociceptive 
afferent nerves by reducing their transduction thresholds and by inducing the expression and recruitment of previously silent nociceptors.,

Important molecular mechanisms involved in peripheral sensitization are: the transient receptor potential vallinoid (TRPV) receptors 1 and 4, the protease activated receptor $2(\operatorname{PAR}(2))$, nitric oxide (NO) pathways, mast cells, enterochromaffin (EC) cells, 5-HT pathways and voltagegated sodium channels (VGSCs).

Transient receptor potential vallinoid receptors and protease activated receptors TRPV1 and 4 are members of a larger family of TRPV channels that serve many sensory functions ranging from hearing to mechanosensory transduction. 5,6 The TRPV1 receptor may be activated by heat as well as exogenous ligands such as capsaicin and its analogues, and is thought to play an important role in mechanotransduction in the GI tract and to the development and maintenance of $\mathrm{VPH} .^{7,8}$

TRPV1 channels are highly expressed on visceral spinal afferents and colocalize with nerve growth factor receptor (trk-A). They are selectively expressed on peptidergic neurons (neurons which express CGRP and SP). ${ }^{9,10}$ TRPV1-activated afferents release inflammatory peptides (CGRP and SP to produce neurogenic inflammation, glutamate. TRPV1 plays a significant role in gastrointestinal inflammation and hypersensitization. ${ }^{11-13}$

TRVP4 is a mechanotransductive osmosensitive channel. The TRPV4 receptor closely interacts with PAR(2) which is expressed by nociceptive neurons in the gut and agonists of $\operatorname{PAR}(2)$ have been found to cause hyperexcitability of intestinal sensory neurons. ${ }^{14}$ Inhibition of serine proteases in vitro reduces sensory afferent nerve discharge, thereby possibly preventing TRPV4 and PAR(2) sensitization). ${ }^{15}$ TRPV4 may present a particularly exciting potential therapeutic target for the future owing to its preferential distribution within the colon.

Increased numbers of mast cells (which release bradykinin and histamine) have been noted in the mucosa of irritable bowel syndrome patients which may persist in the gut lining, contributing to hypersensitivity. Hence, histamine, prostaglandins and interleukins, remain potential therapeutic targets in functional bowel disorders. ${ }^{16}$

\section{Voltage-gated sodium channels}

Certain VGSC isoforms (Nav1.3-1.9) are predominantly expressed in peripheral sensory afferent neurones and may play an important role in generation of PS. This in turn, induces a constellation of changes at the spinal dorsal horn by the activation intracellular signalling cascades. ${ }^{17}$ This may lead to central sensitization (CS) and amplification of the nociceptive response to the stimuli (secondary hyperalgesia) and previously innocuous stimuli may provoke a nociceptive response (allodynia).

The spinal primary afferent neurones have an axon projecting to the gut, a cell body and nucleus in the dorsal root ganglion, and synapse on to a second-order neurone in the dorsal horn of the spinal cord.

Distension can directly activate mechano-receptors on the spinal primary afferent nerves or indirectly by stimulation of IPANs, both eventually leading to stimulation of dorsal horn. Mucosal enteroendocrine cells serve as transducers for the primary afferent nerves. Stimulation of the mucosa of the gut triggers the release of serotonin (5-HT) (and other peptides). Serotonin then diffuses to the nerve endings of enteric nervous system sensory nerves (IPANs) and stimulates them. IPANs control peristalsis and secretion of the gut in response to local stimulation. IPANs and possibly spinal afferents are thought to have serotonin-3 receptors which are excitatory. ${ }^{18}$ IPANs also appear to have serotonin-4 receptors. CGRP is released by both IPANs and spinal afferent nerves. Drugs which block 5-HT-3 or 5-HT-4 receptors may reduce the activation of spinal afferents directly, or indirectly by inhibiting IPANs which may interact with spinal afferents. Antagonists for CGRP or capsaicin, a neurotoxin which destroys afferent neurons, block visceral nociception and post-operative ileus. ${ }^{19,20}$

Tachykinin receptors are also present on IPANs and enteric nervous system interneurones. Substance P, neurokinin A and neurokinin B stimulate the neurokinin 1,2 and 3 receptors, respectively, with greatest efficiency. Neurokinin 2 receptors appear to be on smooth muscle and sensory neurones, as well as in the central nervous system. Neurokinin 3 receptors are on IPANs as well as in the central nervous system. Antagonists to these receptors could be effective as visceral analgesics.

Proteinase-activated receptors (PARs) are G-proteincoupled receptors activated by proteinases that expose a tethered ligand which can auto-stimulate the receptor. Alternatively, synthetic peptides can stimulate the receptors without proteinase activity. ${ }^{21}$

Spinal afferent neurones transmit nociceptive (painful) signals to the dorsal horn of the spinal cord. Immunohistochemical studies have indicated that the primary neurotransmitters of the spinal afferent nerves are CGRP and substance P. CGRP appears to be most relevant to acute pain, as intravenous infusion of CGRP increases visceral pain in animals, and blockade of CGRP with antagonists markedly inhibits visceral pain. ${ }^{22}$ Conversely, antagonists to substance $\mathrm{P}$ have been underwhelming as analgesics. Substance $\mathrm{P}$ appears to be more important as a mediator of spinal sensitization and inflammation. $^{23}$ 


\section{5-HT3-receptor antagonists}

The mechanism(s) by which abdominal pain and discomfort are reduced remains to be determined, but are unlikely due to a peripheral visceral analgesic effect as originally suggested. They may involve attenuating effects on central targets in the brain and spinal cord. ${ }^{24}$ While peripheral receptors on vagal afferents may actually mediate pronociceptive effects. Owing to rare but potentially serious side effects (ischemic colitis and severe constipation), the first such drug approved for use in female IBS patients with diarrhea (alosetron) is only available within a restricted access program. Two newer compounds, a selective 5-HT3R antagonist (DPP-733) and a combined norepinephrine (NE) reuptake inhibitor and 5-HT3R antagonist (NARI) have been evaluated in small clinical trials. $^{25}$

\section{5-HT4R agonists}

The marketing of tegaserod, the first commercially available 5- HT4 receptor agonist, was suspended in March 2007, when an analysis of the data from clinical trials identified a significant increase in the number of cardiovascular ischemic events.

\section{Probiotics}

Beneficial effects of probiotics on gastrointestinal functions have been proposed based on their ability to modulate pathogenic bacteria adherence, enhance barrier function of the epithelium, alter mucosal response to stress as well as from their immunomodulatory properties.

Escherichia coli Nissle 1917 (EcN), Lactobacillus paracasei, Lactobacillus acidophilus have been tried in animal models with varying success but definitive clinical data are not encouraging.

\section{Adrenergic agonists}

Adrenergic receptor modulators- Similar to 5-HT receptors, $\alpha$ adrenergic receptors are widely distributed within the brain-gut axis and have the potential to modulate sensitivity of visceral afferents, spinal cord transmission, and central pain modulation. ${ }^{26}$

In an exploratory RCT of clonidine in IBS-D patients, clonidine was associated with satisfactory symptoms relief compared to placebo. ${ }^{27}$

\section{Kappa opioid receptor agonists}

Fedotozine is a $\kappa$ opioid receptor (KOR) preferring agonist for which a peripheral antinociceptive mechanism of action had been proposed based on several studies in rodent models. Even though a small number of phase IIa studies in IBS patients suggested a possible visceral analgesic effect, the majority of human studies, including two well-designed phase IIb studies were negative and further development of this compound was discontinued. Asimadoline, a different KOR agonist, failed to reduce the severity of abdominal pain in IBS patients with ondemand dosing schedule. Asimadoline is a selective $\kappa$ opiod receptor agonist. A recent large (596 patients), randomized, placebo-controlled, 12-week, asimadoline $(0.5 \mathrm{mg})$ produced significant improvement on total number of months with adequate relief of IBS pain or discomfort, pain scores, and pain free days in IBS-D patients with at least average moderate pain. ${ }^{28-30}$

\section{Antidepressants}

Preclinical and clinical evidence supports the effectiveness of tricyclic antidepressants (TCAs) in neuropathic pain. In addition, the effect of SSRIs and particularly norepinephrine (NE)-serotonin (5-HT) reuptake inhibitor (NSRI) on enhancing the effectiveness of endogenous pain inhibition systems has been suggested. Despite the attractive rationale for using these centrally acting drugs in IBS patients, strong supportive evidence from well-designed clinical trials in IBS patients is currently not available.

\section{Low-dose tricyclic antidepressants}

TCAs, although not FDA approved for IBS, are frequently used to treat IBS and while several randomized, placebo-controlled trials have supported the use of low-dose TCAs in the treatment of IBS patients. A systematic review of TCA trials for IBS failed to observe a beneficial effect of TCA on global IBS symptoms or abdominal pain, mainly because of insufficient statistical power (although they were effective against depressive and anxiety symptoms). ${ }^{31,32}$

\section{SSRIs (selective serotonin reuptake inhibitors)}

SSRIs may have beneficial effect in IBS patients through central effects by reducing both anxiety and pain, yet, their efficacy for IBS remains to be confirmed. Newer monoamine reuptake inhibitors, such as the 5-HT and NE reuptake inhibitors (SNRIs) duloxetine and venlafaxine have been proposed as more effective treatments for chronic pain conditions associated with depression, and while they have been evaluated in patients with painful diabetic neuropathy and fibromyalgia, their effect in IBS remain to be evaluated.

\section{Pregabalin}

Pregabalin (Lyrica), is a second-generation $\alpha 2 \delta$ ligand that is approved for the treatment of neuropathic pain and epilepsy. Although its mechanism of action for pain relief remains unclear, it is believed to bind potently to the two auxiliary proteins associated with voltage-gated calcium channels, reducing depolarization-induced calcium influx at the nerve terminals, and consequently reducing the release of several excitatory neurotransmitters. ${ }^{33}$ 


\section{NK-1 Receptors}

Substance $\mathrm{P}$ is expressed in a greater percentage of visceral afferent fibers than somatic afferent fibers. Inflammation of viscera increases central and peripheral NK1 receptor expression, and visceral hyperalgesia is attenuated in NK1 receptor knockout mice. Receptor antagonists act peripherally and centrally to attenuate visceromotor responses and receptor internalization induced by colorectal distention. Other neuropeptides that have similar potential for a role in visceral pain sensation include CGRP, somatostatin and cholecystokinin.

Somatostatin influences motility and increases gastrointestinal transit time. ${ }^{34}$ Octreotide also blocked bradykinin activation of mesenteric afferents and improved symptom behaviors of irritable bowel syndrome in animals.

\section{SPINAL CORD}

Prostaglandin E2 (PGE2) and the n-methyl d-aspartate (NMDA) receptor have been elucidated as the most importance molecular factors in the development of CS at the spinal dorsal horn. ${ }^{35}$ Human pharmacological studies have demonstrated that antagonism of the PGE2 or the NMDA receptor prevents the development of CS within the oesophagus and antagonism of the NMDA receptor with ketamine may even reverse established $\mathrm{VPH} .{ }^{36,37}$

\section{NMDA Receptors}

NMDA receptors are expressed in primary afferents and dorsal horn neurons. Most models of visceral pain show NMDA receptor activity at the afferent and/or spinal cord level. While NMDA receptors are involved in signaling acute innocuous and noxious visceral pain and inflammatory visceral pain in animals, they do not appear to signal innocuous stimuli in humans during esophageal stimulation. Other glutamate activated receptors such as AMPA channels or the metabotropic glutamate receptor families clearly have a role in nociceptive systems, but specific roles in visceral pain systems are yet to be precisely defined. Recently, riluzole (glutamate uptake enhancer and NMDA receptor antagonist) was proposed to improve visceral hypersensitivity symptoms in animal models. $^{38} \mathrm{~A}$ small clinical comparative effectiveness study on 108 patients indicates superiority of "add on riluzole regimen" to standard IBS therapy, in relieving diarrheal and pain symptoms compared to "add on amitriptyline" or the standard therapy alone. ${ }^{39}$

The dorsal horn of the spinal cord is a critical area in which the modulation of sensitivity can occur. The neurotransmitters substance $\mathrm{P}$, neurokinin $\mathrm{B}$, the $\mathrm{N}$ methyl-d-aspartate receptor and nitric oxide are important in sensitization at the spinal level. Dorsal horn neurons can be stimulated to increase their sensitivity (reduce the threshold to depolarization) by activation of the neurokinin 1 and N-methyld- aspartate receptors. These receptors are stimulated by substance $\mathrm{P}$ and excitatory amino acids, such as glutamate, respectively. Each of these receptors upregulates the effect of the other, leading to a mutually activating cycle and hypersensitivity. ${ }^{40}$ Activated N-methyl-d-aspartate receptors, in turn, stimulate inducible nitric oxide synthase to produce nitric oxide, another mediator of spinal hypersensitivity. ${ }^{41}$ The mutually excitatory system can be inhibited to turn down hypersensitivity by c-aminobutyric acid-b and opiate receptors on dorsal horn neurons. Opiate release is stimulated by neurokinin 3 receptor activation.

\section{Prostaglandin Receptors}

Prostaglandins, synthesized in response to tissue injury by COX, sensitize afferents to mechanical and thermal stimuli and contribute to spinal processing of pain. ${ }^{36}$ In the GI tract constitutive COX1 is involved in gastric mucosal protection, and inducible $\mathrm{COX} 2$ contributes to afferent sensitization. Thus while nonsteroidal antiinflammatory drugs inhibit prostaglandin synthesis and attenuate inflammation and pain, they also damage the gastric mucosa. Current generation COX2 selective inhibitors have limited therapeutic potential due to side effects. Cytokines and other neuroactive substances associated with inflammation (e.g. IL6, TNF-alpha) also have clear role when visceral inflammatory processes have been identified. Various receptors at periphery and in spinal cord have been summarized in Figure 1.
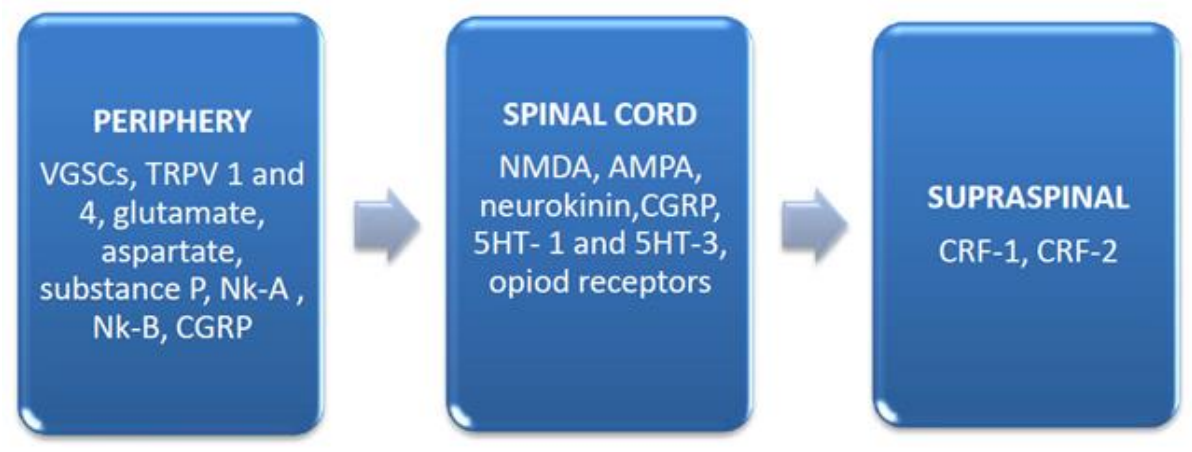

Figure 1: Schematic diagram indicating locations of various receptors/neurotransmitters in the brain-gut axis. 


\section{SUPRASPINAL}

Peripheral and central sensitizations are not exclusive entities in explaining VPH in humans. Central processing of nociception involves input to a number of cortical and subcortical brain structures. From the dorsal horn, neural signals ascend via the spinothalamic, spinoreticular and dorsal column pathways to the brainstem and thalamus. The brainstem and thalamus relay noxious sensory signals to sensory and limbic cortical sites, where discriminative and affective ratings of sensations are determined. There are medial and lateral pain processing pathways. The medial pathway is thought to mediate the emotional or affective component to pain. Pain involves a fear of tissue injury and associated emotions, such as suffering. As expected, the medial pain pathway involves brain circuits crucial to emotional processing, including the intra-laminar thalamus and the anterior cingulate. ${ }^{42}$ These are components of the limbic system, which mediates emotion. Noxious afferent signals from the dorsal horn activate neurones in the thalamus and anterior cingulate. The thalamus relays the signal to the anterior cingulate. The anterior cingulate is an integrative brain centre involved in emotion, attention and pain. ${ }^{43}$

The brain's stress system prominently includes corticotropin- releasing factor (CRF), which is released by the hypothalamus during stress and activates the hypothalamic-pituitary-adrenal axis to produce the stress hormone cortisol. CRF release is stimulated by the limbic system, particularly the amygdale. ${ }^{44}$ CRF neurons activate the locus coeruleus in the brainstem, which facilitates intestinal sensitivity in animals as well as general arousal. CRF infused peripherally in humans can increase the sensitivity of the gut to levels seen in irritable bowel syndrome. CRF is another possible target for the pharmacotherapy of functional bowel disorders. CRF-1 receptors in the central nervous system and peripherally mediate stress-induced increases in colonic motility (Figure 2). ${ }^{45,46}$

CRF-1 antagonists may have anti-depressant effects in humans. ${ }^{47}$ CRF-2 receptors in the brain mediate delayed gastric emptying with stress, whilst peripheral CRF-2 receptors mediate postsurgical ileus. ${ }^{48}$ Which receptor is more relevant to functional bowel disorders and hypersensitivity is unclear, although antagonists to CRF1 would appear to be more promising for irritable bowel syndrome therapy. Non-pharmacological approaches to functional bowel disorders, such as psychotherapy, hypnosis and placebos, appear to be effective. The frontal cortex integrates the sensory and affective dimensions of noxious stimuli, interprets them and plans a response.

Recent technological advances in many functional brain imaging techniques, such as functional magnetic resonance imaging (fMRI), positron emission tomography (PET), magnetoencephalography (MEG), electroencephalography (EEG) and cortical evoked potentials (CEPs) Abnormal areas of activation have been observed in other areas such as the anterior cingulate cortex (ACC), amygdala and brainstem in IBS patients suggesting that the aberrant visceral nociception observed in this group may be, in part, due to central mechanisms. ${ }^{49-53}$

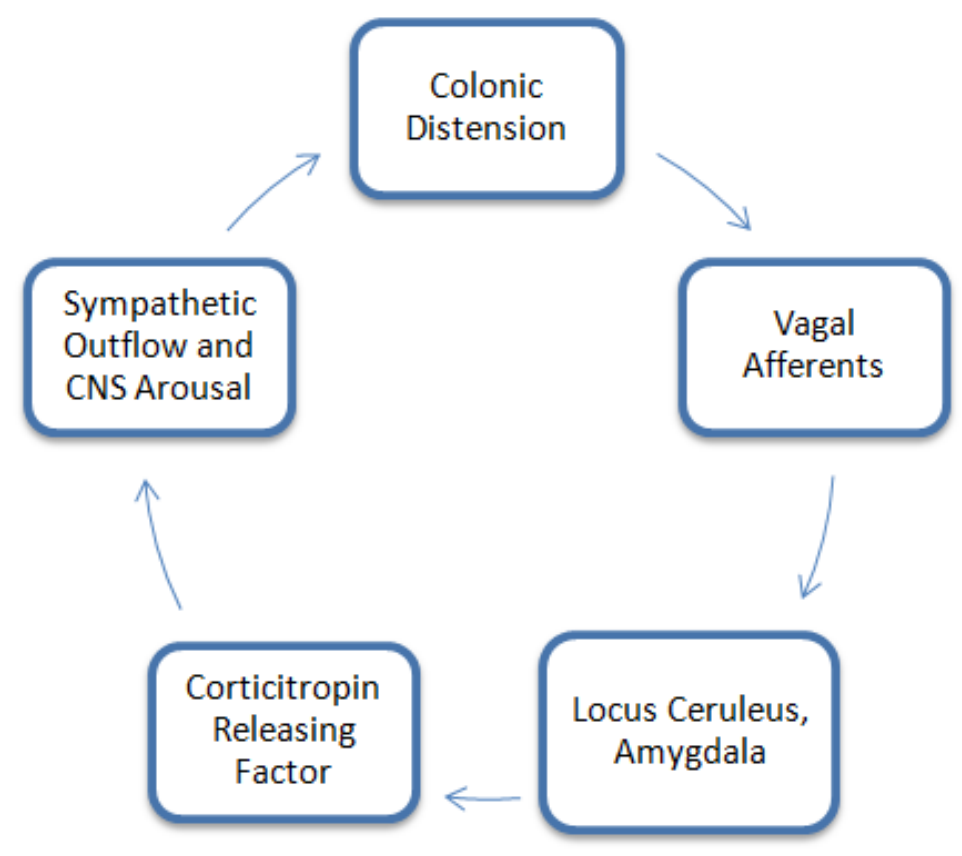

Figure 2: A schematic diagram showing the vicious cycle between colonic distension and CNS arousal. 


\section{Hypothalamic-pituitary-adrenal axis}

The HPA axis exerts important influences on GI motility, sensation and immune function. Irrespective of IBS subtype as defined by predominant stool consistency, there was over activity of the HPA axis and an excess of the pro-inflammatory cytokines interleukin (IL)- 6 and IL- $8 .{ }^{54}$

CRF is up-regulated in response to intestinal inflammation, stress and psychopathologies such as anxiety and depression and has recently been shown to mediate enhanced visceral nociception in a rat model of VPH. CRF receptor subtype $1(\mathrm{CRF}(1))$ plays an important role in the development and maintenance of VPH induced by repeated stress. CRF(1) antagonists inhibit the development of VPH in rat models 90 and represent a novel target for drug development. ${ }^{55}$ In humans, a recent study from Sagami et al. reported an inhibitory effect of intravenous injection of the CRFreceptor antagonist $\alpha$-helical CRF9-41 on abdominal pain and anxiety scores in a model of colonic distension and electrical stimulation of the rectal mucosa in IBS-D patients. ${ }^{56}$ As this compound is not thought to cross the blood- brain barrier, the findings suggest the possibility that antagonism of peripheral CRF1R may have therapeutic effects in IBS patients. By contrast, a recent preliminary report on a clinical trial in female IBS-D patients with the selective CRF1R antagonist Bms562086 did not show any significant effects on IBS symptoms (GI transit and bowel habits). ${ }^{57}$

\section{CRF2R agonists}

CRF has been shown to have receptor-based bimodal effects on multiple physiological responses, such as gastrointestinal motility and stress. Similarly, a divergent role of the CRF receptor subtypes has been suggested in the modulation of visceral pain. While the CRF1 receptor is involved in a pronociceptive effect of CRF, the CRF2 receptor can exert antinociceptive effects at both the peripheral and spinal level. ${ }^{58}$

\section{CONCLUSION}

Nk-1, Nk-2 antagonists, Octreotide, CFR-1 and CRF-2 antagonists are still in phase I of clinical trials whereas citalopram (SSRI), probiotics (Lactobacillus farciminis), alpha 2b agonist (AGN 203818) and AGN 203818 (SNRI) are currently undergoing phase II. Even though the molecular targets are very promising in pre-clinical studies, their success rate in clinical studies has not been as encouraging. A better characterization of normal as well as abnormal visceral pain perception (e.g. central pain amplification) and underlying mechanisms (sensory, cognitive, and emotional) in human patients is required before more effective drug development is possible. The visceral hypersensitivity in IBS has apparently has diverse pathogenesis. Understanding of common elements at critical steps that should be subject to targeting by new agents modulating neurophysiological processes may render useful therapeutic agents.

Alternately, the emerging concepts of synergy among modulatory interventions, is relevant to be explored in case of IBS. Right combination of measure may thus be devised in patient centered therapeutic approach.

Funding: No funding sources

Competing interests: None declared

Ethical approval: Not required

\section{REFERENCES}

1. Farthing MJ. Irritable bowel, irritable body, or irritable brain? BMJ 1995;310:171-5.

2. Bradesi S, Herman J, Mayer EA. Visceral analgesics: drugs with a great potential in functional disorders? Curr Opin Pharmacol 2008;8:697-703.

3. Yu S, Ouyang A. TRPA1 in Bradykinin-induced mechano-hypersensitivity of vagal $\mathrm{C}$ fibers in guinea pig esophagus. Am J Physiol Gastrointest Liver Physiol 2009;296:G255-65.

4. Jones RC 3rd, Xu L, Gebhart GF. The mechanosensitivity of mouse colon afferent fibers and their sensitization by inflammatory mediators require transient receptor potential vanilloid 1 and acid-sensing ion channel 3. J Neurosci 2005;25:10981-9.

5. Winston J, Shenoy M, Medley D, Naniwadekar A, Pasricha PJ. The vanilloid receptor initiates and maintains colonic hypersensitivity induced by neonatal colon irritation in rats. Gastroenterology 2007; 132:615-27.

6. Levine JD, Alessandri-Haber N. TRP channels: targets for the relief of pain. Biochim Biophys Acta 2007;1772:989-1003.

7. Winston J, Shenoy M, Medley D, Naniwadekar A, Pasricha PJ. The vanilloid receptor initiates and maintains colonic hypersensitivity induced by neonatal colon irritation in rats. Gastroenterology 2007;132:615-27.

8. Holzer P. TRPV1 and the gut: from a tasty receptor for a painful vanilloid to a key player in hyperalgesia. Eur J Pharmacol 2004;500:231-41.

9. Hwang SJ, Valtschanoff JG. Vanilloid receptor VR1-positive afferents are distributed differently at different levels of the rat lumbar spinal cord. Neurosci Lett 2003;349:41-4.

10. Guo A, Vulchanova L, Wang J, Li X, Elde R. Immunocytochemical localization of the vanilloid receptor 1 (VR1): relationship to neuropeptides, the P2X3 purinoceptor and IB4 binding sites. Eur J Neurosci 1999;11:946-58.

11. Jones RC 3rd, $\mathrm{Xu}$ L, Gebhart GF. The mechanosensitivity of mouse colon afferent fibers and their sensitization by inflammatory mediators require transient receptor potential vanilloid 1 and acid-sensing ion channel 3. J Neurosci 2005;25:10981-9. 
12. Szallasi A, Cortright DN, Blum CA, Eid SR. The vanilloid receptor TRPV1: 10 years from channel cloning to antagonist proof-of-concept. Nat Rev Drug Discov 2007;6:357-72.

13. Geppetti P, Trevisani M. Activation and sensitisation of the vanilloid receptor: role in gastrointestinal inflammation and function. $\mathrm{Br} \mathrm{J}$ Pharmacol 2004;141:1313-20.

14. Sipe WE, Brierley SM, Martin CM et al. (2008) Transient receptor potential vanilloid 4 mediates protease activated receptor 2 -induced sensitization of colonic afferent nerves and visceral hyperalgesia. Am J Physiol Gastrointest Liver Physiol 2008;294:G1288-98.

15. Barbara G, Wang B, Stanghellini V et al. Mast celldependent excitation of visceral-nociceptive sensory neurons in irritable bowel syndrome. Gastroenterology 2007;132:26-37.

16. Spiller RC, Jenkins D, Thornley JP, et al. Increased rectal mucosal enteroendocrine cells, $\mathrm{T}$ lymphocytes, and increased gut permeability following acute (Campylobacter) enteritis and in post-dysenteric irritable bowel syndrome. Gut 2000;47:804-11.

17. Anand P, Aziz Q, Willert R, van Oudenhove L. Peripheral and central mechanisms of visceral sensitization in man. Neurogastroenterol Motil 2007;19:29-46.

18. Barbara G, Wang B, Stanghellini V et al. Mast celldependent excitation of visceral-nociceptive sensory neurons in irritable bowel syndrome. Gastroenterology 2007;132:26-37.

19. Toda N, Kishioka S, Hatano Y, Toda H (2009) Modulation of opioid actions by nitric oxide signaling. Anesthesiology 2009;110:166-81.

20. Takeuchi K, Yokota A, Tanaka A, Takahira Y. Factors involved in upregulation of inducible nitric oxide synthase in rat small intestine following administration of nonsteroidal anti-inflammatory drugs. Dig Dis Sci 2006;51:1250-9.

21. Vergnolle N, Bunnett N, Sharkey K, et al. Proteinase-activated receptor-2 and hyperalgesia: a novel pain pathway. Nature Med 2001;7:772-3.

22. Plourde V, Piere SS, Quirion R. Calcitonin generelated peptide in viscerosensitive response to colorectal distension in rats. Am J Physiol 1997;273:G191-6.

23. Yaksh TL, Hua X-Y, Kalcheva I, et al. The spinal biology in humans and animals of pain states generated by persistent small afferent input. Proc Natl Acad Sci USA 1999;96:7680-6.

24. Suzuki R, Rygh LJ, Dickenson AH. Bad news from the brain: descending 5-HT pathways that control spinal pain processing. Trends Pharmacol Sci 2004;25:613-7.

25. Paterson WG, Ford D, Ganguli SC, Reynolds RP, Pliamm L, O’Mahony M, Pare P, Nurbhai S, Feagan B, Landau SB. A novel, oral 5HT3 partial agonist, DDP-733, improves overall response in patients with irritable bowel syndrome and constipation
(IBS-C): a randomized, double-blind, placebocontrolled, parallel-group, dose-ranging study. Gastroenterology 2008;134:A546-7.

26. Pertovaara A. Noradrenergic pain modulation. Prog Neurobiol 2006;80:53-83.

27. Camilleri M, Kim DY, McKinzie S, Kim HJ, Thomforde GM, Burton DD, Low PA, Zinsmeister AR. A randomized, controlled exploratory study of clonidine in diarrhea-predominant irritable bowel syndrome. Clin Gastroenterol Hepatol 2003;1:11121.

28. Dapoigny M, Abitbol JL, Fraitag B. Efficacy of peripheral k-agonist fedotozine versus placebo in treatment of irritable bowel syndrome: a multicenter dose-response study. Digest Dis Sci 1995;40:22449.

29. Szarka LA, Camilleri M, Burton D, Fox JC, McKinzie S, Stanislav T, Simonson J, Sullivan N, Zinsmeister AR. Efficacy of on-demand asimadoline, a peripheral kappa-opioid agonist, in females with irritable bowel syndrome. Clin Gastroenterol Hepatol 2007;5:1268-75.

30. Mangel AW, Bornstein JD, Hamm LR, Buda J, Wang J, Irish W, Urso D. Clinical trial: asimadoline in the treatment of patients with irritable bowel syndrome. Aliment Pharmacol Ther 2008;28:23949.

31. Clouse RE. Antidepressants for irritable bowel syndrome. Gut 2003;52:598-9.

32. Brandt LJ, Bjorkman D, Fennerty MB, Locke GR, Olden K, Peterson W, Quigley E, Schoenfeld P, Schuster M, Talley N. Systematic review on the management of irritable bowel syndrome in North America. Am J Gastroenterol 2002;97(11 Suppl):S7-S26.

33. Ben-Menachem E. Pregabalin pharmacology and its relevance to clinical practice. Epilepsia 2004;45 (Suppl 6):13-8.

34. O'Donnell LJ, Watson AJ, Cameron D, Farthing MJ. Effect of octreotide on mouth-to-caecum transit time in healthy subjects and in the irritable bowel syndrome. Aliment Pharmacol Ther 1990;4:177-81.

35. Grundy D, Al-Chaer ED, Aziz Q, et al. Fundamentals of neurogastroenterology: basic science. Gastroenterology2006;130:1391-1411.

36. Sarkar S, Hobson AR, Hughes A, et al. The prostaglandin E2 receptor-1 (EP-1) mediates acidinduced visceral pain hypersensitivity in humans. Gastroenterology 2003;124:18-25.

37. Willert RP, Woolf CJ, Hobson AR, Delaney C, Thompson DG, Aziz Q. The development and maintenance of human visceral pain hypersensitivity is dependent on the N-methyl-D-aspartate receptor. Gastroenterology 2004;126:683-92.

38. Gosselin RD, O'Connor RM, Tramullas M, JulioPieper M, Dinan TG, Cryan JF. Riluzole normalizes early-life stress-induced visceral hypersensitivity in rats: role of spinal glutamate reuptake mechanisms. Gastroenterology 2010;138:2418-25. 
39. Mishra SP, Shukla SK, Pandey BL. Evaluation of riluzole and contemporary therapies in management of visceral hypersensitivity aspect of irritable bowel syndrome and functional dyspepsia, thesis: Banaras Hindu University, July 2012.

40. Dubner R, Ruda MA. Activity-dependent neuronal plasticity following tissue injury and inflammation. Trends Neurol Sci 1992;15:96-103.

41. Coutinho S, Urban M, Gebhart G. The role of CNS NMDA receptors and nitric oxide in visceral hyperalgesia. Eur J Pharmacol 2001;429:319-25.

42. Jessell T, Kelly D. Pain and analgesia. In: Kandel E, Schwartz J, Jessell T, eds. Principles of Neuroscience, 3rd edn. Norwalk, CT: Appleton \& Lange, 1991:385-99.

43. Devinsky O, Morrell MJ, Vogt BA. Contributions of anterior cingulate cortex to behavior. Brain 1995; 118:279-306.

44. Gue M, Tekamp A, Tabis N, et al. Cholecystokinin blockade of emotional stress- and CRF-induced colonic motor alterations in rats: role of the amygdala. Brain Res 1994;658:232-8.

45. Tache Y, Martinez V, Million M, et al. Stress and the gastrointestinal tract III. Stress-related alterations of gut motor function: role of brain corticotropin-releasing factor receptors. Am J Physiol 2001;280:G173-7.

46. Maillot C, Million M, Wei J, et al. Peripheral corticotropin releasing factor and stress-stimulated colonic motor activity involve type 1 receptor in rats. Gastroenterology 2000;119:1569-79.

47. Zobel A, Nickel T, Kunzel H, et al. Effects of highaffinity corticotropin-releasing hormone receptor 1 antagonist R121919 in major depression: the first 20 patients treated. J Psychiatr Res 2000;34:171-81.

48. Tache Y, Martinez V, Million M, et al. Stress and the gastrointestinal tract III. Stress-related alterations of gut motor function: role of brain corticotropin-releasing factor receptors. Am J Physiol 2001;280:G173-7.

49. Hobson AR, Aziz Q. Brain imaging and functional gastrointestinal disorders: has it helped our understanding? Gut 2004;53:1198-1206.
50. Sharma A, Lelic D, Brock C, Paine P, Aziz Q. New technologies to investigate the brain-gut axis. World J Gastroenterol 2009;15:182-91.

51. Mayer EA (2000) Spinal and supraspinal modulation of visceral sensation. Gut 2000;47(Suppl 4):iv69-iv72.

52. Chang L, Berman S, Mayer EA, et al. Brain responses to visceral and somatic stimuli in patients with irritable bowel syndrome with and without fibromyalgia. Am J Gastroenterol 2003;98:1354-61.

53. Coen SJ, Aziz Q, Yaguez L, Brammer M, Williams SC, Gregory LJ. Effects of attention on visceral stimulus intensity encoding in the male human brain. Gastroenterology 2008;135:2065-74, 2074 e1.

54. Dinan TG, Quigley EM, Ahmed SM et al. Hypothalamic-pituitary-gut axis dysregulation in irritable bowel syndrome: plasma cytokines as a potential biomarker? Gastroenterology 2006;130:304-11.

55. Martinez V, Tache Y. CRF1 receptors as a therapeutic target for irritable bowel syndrome. Curr Pharm Des 2006;12:4071-88.

56. Sagami Y, Shimada Y, Tayama J, Nomura T, Satake M, Endo Y, Shoji T, Karahashi K, Hongo M, Fukudo S. Effect of a corticotropin releasing hormone receptor antagonist on colonic sensory and motor function in patients with irritable bowel syndrome. Gut 2004;53:958-64.

57. Sweetser SR, Nord SJL, Burton DD, Grudell A, Eckert DJ, Manini ML, et al. Effects of a novel corticotrophin releasing factor receptor-1 antagonist, Bms-562086, on gastrointestinal and colonic transit and bowel habits in patients with diarrheapredominant irritable bowel syndrome (D-IBS). Gastroenterology 2008;134(4 Suppl 1):A-548.

58. Martinez V, Barquist E, Rivier J, et al. Central CRF inhibits gastric emptying of a nutrient solid meal in rats: the role of CRF2 receptors. Am J Physiol 1998;274:G965-70.

doi:10.5455/2319-2003.ijbcp20130303

Cite this article as: Mishra S, Singh A, Pandey BL. Current state of pharmacology and therapeutics in irritable bowel syndrome with special reference to brain-gut axis. Int J Basic Clin Pharmacol 2013;2:122-9. 